\title{
Empresas intensivas em conhecimento: internacionalização, interação com o Estado e com a universidade
}

\author{
Diogo Serafim Schmidt, Juliana Passos de Mello \& Lucas Silveira \\ de Moura*
}

\begin{abstract}
Resumo: Este artigo elabora sobre dados produzidos pela pesquisa realizada pela prof ${ }^{\mathrm{a}}$. S. K. Guimarães ${ }^{1}$, que analisou seis empresas intensivas em conhecimento, bem sucedidas em suas atividades de inovação e de internacionalização. Segundo a autora, o interesse do tema decorre da relevância da inovação e internacionalização para o desenvolvimento econômico sustentável, na atualidade. 0 artigo examina os processos de internacionalização a partir do exame de condições institucionais e sócio-econômicas, bem como, valores presentes entre os empreendedores, que os fazem perseguir a internacionalização, apesar das dificuldades, em um país como o Brasil. Essas questões foram examinadas por meio de entrevistas semiestruturadas realizadas entre empreendedores de empresas internacionalizadas. 0 presente artigo estendeu a análise, utilizando-se dos dados já coletados, de alguns resultados produzidos pela pesquisa acima indicada e, também, pelo survey realizado pelo mesmo grupo. Alguns estudos afirmam que na chamada economia do conhecimento, para que se efetive a inovação qualificada, capaz de alcançar a internacionalização, seria fundamental consolidar a interação entre empresa, universidade e Estado. Partindo deste pressuposto, este artigo foca sobre a natureza da interação entre empresas, universidades e Estado, nas empresas investigadas.
\end{abstract}

Palavras-chave: inovação tecnológica, hélice tríplice, internacionalização.

\section{Introdução}

O estudo partiu da necessidade de conhecer, ainda que de forma incipiente, os fenômenos que caracterizam o denominado capitalismo informacional (CASTELLS, 1999) ou sociedade da informação e que impõem sérios desafios às economias emergentes, como o Brasil. Sendo a inovação o motor desse novo estágio do capitalismo, tornou-se necessário estimular a cultura da inovação, por meio de uma aproximação entre o setor produtivo e as principais fontes de conhecimento da sociedade, ou seja, a universidade e os centros de pesquisa, para que se produza a transferência, do conhecimento científico para a empresa, que utilizará o referido

\footnotetext{
* Graduandos em Ciências Sociais - UFRGS.

${ }^{1}$ A referida pesquisa resultou no artigo "International entrepreneurship in an emergent economy" (GUIMARÃES, 2011).
} 
conhecimento para a geração de inovação - conhecimento aplicado, transformado em produto, serviço ou processo, a ser disponibilizado para o mercado. Outro agente igualmente relevante no novo contexto é o Estado. 0 modelo de interação entre universidade, empresa e Estado é denominado, por Etzkowitz (2009), de "hélice tríplice" e, segundo o autor, a importância dessa aliança decorre da complexidade e rapidez das mudanças tecnológicas atuais, baseadas em conhecimento científico. Contudo, a transferência do conhecimento não é automática; a interação universidade-empresa permite acelerar esse processo, enquanto o Estado deve criar incentivos e estímulos para que se desenvolva um ambiente propício à inovação. Cada elemento da hélice tríplice desempenha seu próprio papel e interage com o outro para possibilitar a inovação, preservando suas características e autonomia. A universidade produz conhecimento, a empresa é o ator-chave e lócus de produção e o Estado é a fonte de relações contratuais que possibilitam interações estáveis e o intercâmbio entre os atores.

Ao mesmo tempo, segundo o modelo da hélice tríplice, as interações permitem que cada ator "assuma o papel do outro", sem perder seus papéis originais e suas identidades distintas (ETzkowitz, 2009). A universidade estimula o surgimento de novas empresas a partir da pesquisa científica, introduzindo a "capitalização do conhecimento" como um objetivo acadêmico. As empresas agem como universidades ao desenvolver Pesquisa e Desenvolvimento (P\&D) para alcançar níveis mais qualificados de produção, compartilhando o conhecimento por meio de parcerias com organizações científicas e empresariais. 0 Estado mantém sua atividade regulatória, mas também age como capitalista público através de joint ventures (ETZKoWITZ, 2009). A teoria da hélice tríplice considera a universidade como a fonte de empreendedorismo e tecnologia, assim como de novos conhecimentos.

\section{Inovação tecnológica em empresas localizadas em incubadoras ou parques tecnológicos}

Para uma melhor delimitação do tema, apresentamos a definição de inovação tecnológica, utilizada pela PINTEC (2008), baseada, por sua vez, no Manual de Oslo (2004) - principal documento internacional, elaborado pela Organização para a Cooperação e o Desenvolvimento Econômico (OCDE), contendo proposta de diretrizes para coleta e interpretação de dados sobre inovação tecnológica -, definida como a introdução no mercado de um produto (bem ou serviço) novo ou substancialmente 
aprimorado, ou pela introdução na empresa de um processo novo ou substancialmente aprimorado. Essa foi também a definição empregada neste estudo.

A inovação realizada pela empresa pode ser incremental - a grande maioria dos casos, em especial no Brasil - ou, radical, como ocorre, em geral, nos países industrialmente avançados. A inovação incremental é uma melhoria no produto, processo ou na organização da produção no interior de uma empresa, já existente, sem alterar a estrutura industrial, próxima à imitação. No caso de um produto, é considerada inovação incremental, sempre que não houver alteração em suas funções básicas, mesmo que se utilizem novos materiais. Por sua vez, a inovação radical introduz um novo produto, processo ou forma de organização da produção, processando-se mudança significativa. A urna eletrônica brasileira, desenvolvida em Florianópolis, pela Fundação Centros de Referência em Tecnologias Inovadoras (CERTI), pode ser considerada uma inovação radical, por introduzir um novo produto que representou mudança no processamento eleitoral; o voto manual foi substituído pelo voto eletrônico. Entretanto, a inovação radical não é a norma no Brasil, nem foi o resultado encontrado pela pesquisa agora examinada, que evidenciou o nível incremental de inovação das empresas investigadas, ou seja, inovação que não ultrapassa a fronteira científica mundial. Neste artigo não discutiremos a cerca de outros tipos ou categorias de inovação existentes, como a inovação social e a inovação organizacional.

Para melhor compreender o baixo grau de inovação da produção brasileira, deve-se considerar que a industrialização seguiu o modelo baseado na substituição de importações. Para De Negri (2005), o modelo de industrialização substitutiva de importações, vigente pelo menos entre 1930 e 1960, deu musculatura à indústria brasileira, porém, faltou ao Brasil ter como meta a liderança em mercados externos. Alguns países que se destacaram nos anos 80 e 90, como Japão, Coréia do Sul e China, apresentaram um quadro semelhante ao do Brasil, estando a diferença no enfrentamento à competição em mercados internacionais. No final dos anos 80 , após a abertura comercial, a indústria brasileira ressentiu-se das características deixadas pelo modelo de substituição de importações, como acomodação, falta de estímulo para inovar e para criar inovações e, principalmente, para satisfazer os consumidores, em termos de preço e qualidade. No Brasil, a indústria orientou sua produção para o mercado interno e seu esforço tecnológico manteve-se em adaptar ao mercado brasileiro produtos de tecnologia externa. 
Resultados da pesquisa Construção da inovação através de redes de cooperação universidade-empresa: análise das iniciativas e estratégias de cooperação no Rio Grande do Sul ${ }^{2}$ apontaram para o baixo grau de inovação tecnológica da maior parte das 81 empresas intensivas em conhecimento investigadas; contudo, 19 declararam envolvimento com atividades internacionais, o que supõe capacidade de enfrentar competição no mercado mundial. Das 19 empresas internacionalizadas, seis casos considerados bem-sucedidos foram investigados. 0 objetivo da pesquisa, que era exploratória, foi o de conhecer as formas e os mecanismos presentes no processo de internacionalização (considerando não apenas envolvimento com o comércio internacional, mas também atividades como parcerias em $\mathrm{P} \& \mathrm{D}$, joint ventures ou filiais no exterior). Conforme constata a literatura, observa-se a ocorrência de novas dinâmicas nos processos de internacionalização. Em passado recente, os principais envolvidos em processos de internacionalização eram as grandes empresas, contudo, com o desenvolvimento das tecnologias de informação e comunicação (TICs), junto à crescente importância da produção baseada em conhecimento intensivo, esse cenário se transformou. Novos "players in the game" emergem (RuzziER et al., 2006): as pequenas e médias empresas (PMEs). Assim, estamos diante de uma conjuntura em que as PMEs adquirem papel de destaque na economia mundial, mobilizando recursos econômicos e sociais, que diferem dos das grandes empresas e de empresas voltadas para o mercado doméstico.

O cenário econômico mundial se reestrutura, em grande parte, devido ao aumento da relevância da produção de bens e serviços baseados em conhecimento e da crescente descentralização de $\mathrm{P} \& \mathrm{D}$, o que possibilita a emergência do empreendedorismo intensivo em conhecimento, também, em países emergentes, situados fora do antigo eixo principal, dominado pela América do Norte, Europa e Japão.

Em países desenvolvidos como Estados Unidos, Japão, Alemanha, França e Grã-Bretanha, em média, 85\% dos gastos em P\&D se concentram em setores intensivos em tecnologia: eletrônica (25\%), química, farmácia e petroquímica (18\%), aeronáutica (17\%), equipamentos de escritório, instrumentos de precisão e computadores (14\%), automóveis, e outros meios de transporte (11\%) (CARNEIRO, 2008).

\footnotetext{
${ }^{2}$ A pesquisa foi realizada, entre novembro de 2008 e fevereiro de 2010, pelo Grupo de Pesquisa sobre Trabalho na Sociedade Contemporânea da UFRGS.
} 
Contudo, apesar do aumento de investimentos por parte de países emergentes no desenvolvimento de produtos com alto valor agregado pelo conhecimento, o Brasil, líder entre os países da América Latina, ainda tem como característica baixa taxa de exportação de produtos com inovações de alta intensidade tecnológica, prevalecendo a inovação e exportação de produtos com inovação incremental (GUIMARÃEs, 2011).

A literatura sobre empreendedorismo e internacionalização concentra-se em países da Europa e nos Estados Unidos, e tem como característica estudos que enfatizam ou aspectos institucionais ou aspectos subjetivos do empreendedor. Alguns desses estudos partem da concepção de que os processos de internacionalização seriam fruto de um proceso linear, em que a empresa passaria por uma consolidação em seu mercado regional e nacional, e somente depois se internacionalizaria. 0 alicerce dessa ideia é a teoria da psychic distance, que pressupõe que o baixo nível de diferença cultural e a distância geográfica seriam elementos que possibilitariam um maior sucesso nas práticas de internacionalização (KUEMMERE apud Guimarães, 2011). As seis empresas investigadas no estudo de Guimarães, atuavam nos setores de biotecnologia e software. Os produtos são intensivos em tecnologia e as empresas são caracterizadas pelos vínculos com o meio acadêmico. 0 artigo (GUIMARÃEs, 2011) mostra que a internacionalização não possui padrões específicos e que a prática é realizada a partir de diferentes estratégias, de acordo com o setor em que atua a empresa e os valores dos empreendedores. 0 setor de informática é caracterizado por forte dinâmica de inovação, ainda que com predomínio incremental. Os produtos dessa atividade econômica não possuem uma vida muito longa, devido à rapidez das inovações, ao grande número de empresas inovadoras nessa área, e por não serem necessários grandes investimentos para a sua realização. Em contrapartida, o setor de biotecnologia necessita de grande investimento financeiro, devido aos altos custos em P\&D, sendo também um setor onde o dispêndio de tempo é muito elevado, o que aumenta o risco e a incerteza, além de requerer alta qualificação do pessoal ocupado na empresa.

As entrevistas da pesquisa exploratória continham inúmeras informações relevantes sobre a interação dessas empresas internacionalizadas com a universidade e com o Estado que não foram explorados no artigo de Guimarães, e que são analisadas no presente artigo. A hipótese que norteou o estudo que ora apresentamos é de que os possíveis vínculos das empresas com a universidade e com o Estado facilitam 
o processo de internacionalização. Com auxílio do software Nvivo 9, categorizou-se as entrevistas para análise de discurso. Apresentaremos, a seguir, os casos das empresas estudadas no que concerne às relações com a universidade e com o Estado, e demais informações relevantes, ilustradas pelo discurso dos empreendedores. Segue tabela com dados referentes às empresas estudadas:

Tabela 1 - Dados das empresas

\begin{tabular}{cccc}
\hline Empresas & Área de Atuação & Localização & $\begin{array}{c}\text { No de } \\
\text { Funcionários }\end{array}$ \\
\hline A & $\begin{array}{c}\text { TI - Desenvolvimento de } \\
\text { Sistemas }\end{array}$ & PUCRS & 30 \\
B & TI - Desenvolvimento de & Software & 5 \\
C & $\begin{array}{c}\text { Tecnologia Eletrônica } \\
- \text { Entretenimento e } \\
\text { Informação }\end{array}$ & UNISC & 100 \\
D & $\begin{array}{c}\text { Telecomunicações e TI } \\
\text { E }\end{array}$ & UNISINOS & 90 \\
F & Engenharia - Aplicação do & Pzônio & 22 \\
\hline
\end{tabular}

Fonte: os autores.

\section{As entrevistas}

Todas as empresas investigadas mantinham relações, formais em alguns casos e informais em outros, com a universidade. Em relação à interação com o Estado, ficaram evidentes as críticas à dificuldade de acesso aos recursos governamentais; e as dificuldades criadas pela variação cambial, especificamente a valorização do real frente ao dólar, que vigorava à época. Inclusive, a variação cambial foi muito citada como um fator que representava tanto risco de perdas como de ganhos no processo de internacionalização, em decorrência da desvalorização ou valorização do dólar. 
Os empreendedores referem-se à universidade como fonte de produção de conhecimento, informação e inovação, como também, é citada a função da universidade como provedora de estrutura física, no caso de empresas incubadas ou que funcionavam em parques tecnológicos. Em termos de parceria de pesquisa para criação e aprimoramento de bens, produtos ou serviços, detectou-se que cinco das seis empresas investigadas haviam firmado acordos formais com a instituição universitária ou com pesquisadores/doutores atuantes na universidade. Cinco das empresas seguiam o modelo formal de cooperação de pesquisa. A exceção foi a empresa B, cujo empreendedor afirmou que o ambiente em si serve para livre troca de informação e formação de redes, independente de vínculos formais, conforme trecho a seguir:

Tem algumas coisas mais formais, que são serviços que a universidade pode prestar para as empresas, e tem uma coisa mais informal, mais natural do ambiente mesmo. Então, se eu conheço vários professores, por ser incubado aqui e tudo mais, então acabo encontrando, conversando, aí eles conhecem o produto, e estão em sala de aula falando sobre um assunto que está relacionado, e então eles falam que tem uma empresa no pólo que trabalha com isso... Acontece bastante.

As empresas C e E representam o fenômeno do professor/pesquisador empreendedor, pois têm como fundadores, respectivamente, o coordenador do curso de Ciências da Computação de uma das universidades, e no caso da segunda empresa, uma pesquisadora já aposentada cujos sócios são também professores acadêmicos. Ambas as empresas contam com estudantes de graduação e pós-graduação no corpo de funcionários, geralmente indicados pelos próprios professores. Existem diferenças quanto ao nível de escolaridade dos funcionários de acordo com o setor da empresa; as de biotecnologia, por exemplo, necessitam de pessoas com maior qualificação devido à complexidade da atividade. Uma peculiaridade da empresa $\mathrm{C}$ é que ela contratou um aluno intercambista que visitou a universidade, ele conheceu a empresa e tornou-se representante comercial dessa em seu país de origem, um caso no qual a universidade claramente propiciou informalmente a internacionalização da empresa. A empresa E conta com cinco doutores, dois mestres, dois mestrandos, três técnicos da escola da UFRGS, e uma graduanda. Pode-se observar, neste caso, como a universidade serve para a captação de recursos humanos qualificados e, também, segundo a sócia, para questões infraestruturais e de proximidade: 
Parque Tecnológico. Que no nosso caso, é extremamente importante a segurança. Nós trabalhamos dia e noite.

Os sócios das empresas A, D e F contaram com a universidade para parcerias e convênios formais para projetos de pesquisa específicos e para P\&D. A empresa A firmou parcerias com doutores para aprimorar seu serviço de desenvolvimento de softwares customizados e para diferenciar-se no mercado:

Nós temos um projeto desde 2005 com a universidade, como a minha área é software, $e$ desenvolvê-lo é uma coisa que na prática $90 \%$ das empresas desenvolvem artesanalmente, mas eu nunca estive satisfeito com isso. Então eu estou trabalhando com dois doutores de engenharia de software que é para melhorar o processo, trazer mais engenharia para dentro do processo de desenvolvimento.

0 resultado dessa colaboração, segundo o empreendedor, gera novas pesquisas acadêmicas que eventualmente podem servir para a empresa. A empresa D conta com duas equipes de P\&D na UFRGS, além da equipe interna. Outro tipo de parceria, na qual a universidade procura a empresa, também existe, segundo o sócio:

E também tem um outro projeto que a gente ganhou que fizemos com a UFRGS. A UFRGS que ganha, mas eles têm que fazer junto com uma empresa. É um projeto conjunto.

Surgida de um trabalho de conclusão de curso, a empresa F nasceu na universidade, a partir de um grupo de colegas. É a única empresa que mantém convênios com diversas universidades, conforme o empreendedor: "A gente faz toda a parte de P\&D e os convênios com as universidades. A gente gerencia através do Tecnopuc. Somos conveniados com a Unisinos, a UFRGS, a PUCRS, a Feevale, a Univale e a faculdade de Botocatu". Na Unisinos, foi criado um laboratório especificamente para ozônio (objeto de P\&D da empresa), com auxílio da Financiadora de Estudos e Projetos (FINEP), e a empresa procura incentivar pesquisas que no futuro possam gerar produtos ou serviços que terão seu retorno econômico dividido com a universidade.

Nos casos estudados, o governo é representado pelos empreendedores como controlador do aparato burocrático, fonte para obtenção de recursos (financiamento) e subvenções, e como fomentador de redes para a internacionalização. A questão mais abordada foi a do financiamento, em específico, a dificuldade de acesso aos recursos disponibilizados pelo governo. Desde final dos anos 90, os governos têm 
realizado esforços para incentivar a implementação de inovações no país. A criação dos Fundos Setoriais pelo Ministério de Ciência e Tecnologia (MCT), em 1999, as Diretrizes de Política Industrial, Tecnológica e de Comércio Exterior (2003), a Lei de Inovação (2004), Lei no 11.196, de 21/11/2005, ou “Lei do Bem” (2006) e a Política de Desenvolvimento Produtivo (2008), são marcos legais recentes que visam a fomentar a inovação tecnológica no Brasil. A percepção dos empreendedores, entretanto, é de que não tem sido efetivo esse esforço governamental.

Foi unânime a observação, mesmo entre as empresas que conseguiram acesso ao financiamento, sobre a dificuldade de obtê-lo. Estudando os casos específicos, pode-se observar que duas empresas foram contempladas pelo financiamento, mas apenas uma, a empresa $\mathrm{E}$, dentre seis, de fato já conseguiu ter acesso à verba para subsidiar a pesquisa: "Nós passamos quatro anos tentando pedir e não conseguimos nunca (...). Mas hoje qualquer projeto que a gente coloca a gente ganha.". Por outro lado, a empresa A não realiza esforços para acessar os recursos:

Eu não sei, tem um projeto que até a gente pensou em pegar [financiamento], mas como para nós não era uma questão, ou faz o projeto com financiamento ou não faz, e tinha toda uma burocracia que nós teríamos que gastar energia, que eu acho que é certo, eu não estou discutindo isso, então nós achamos por bem, não, vamos deixar pra quem precisa, né?!

Segundo os entrevistados, a especificidade dos editais gera vantagem às empresas que contratam profissionais para elaboração de projetos para lidar com a burocracia inerente a eles; como ilustram, respectivamente, as falas dos empreendedores B e F:

Mas o que acontece é o seguinte: o governo cria um edital distribuindo dinheiro, só que muitas vezes para áreas muito específicas.; e "Aí quem ganha? Ganha a Natura, a Gerdau... E ainda sem subvenção. É um depósito. É muito bonito subvenção econômica da FINEP, etc, etc, mas ele contempla empresas que já são grandes...

A empresa D, que foi contemplada, mas ainda não recebeu o recurso, critica a dificuldade de acesso aos editais, o tempo que o recurso leva até chegar efetivamente ao destino, e aponta a falta de investimento na indústria:

Parece que às vezes o governo acorda, mas a gente estava muito refém disso, então têm coisas que estão começando a acontecer, por outro lado a indústria nacional não tem muito incentivo pra continuar fazendo alguma coisa no Brasil. 
Em termos de relação com o Estado, a questão do financiamento foi a mais referida pelos empreendedores, mas há empresas que mantêm outro tipo de relações com o governo. A empresa $C$ firmou parceria com o Serviço Brasileiro de Apoio às Micro e Pequenas Empresas (SEBRAE) para construção de um laboratório na Universidade Federal de Santa Maria (UFSM), com contrapartida da empresa e parceria com a FINEP para criação de laboratório na Universidade de Santa Cruz do Sul (UNISC), destinado principalmente à pesquisa. A empresa $\mathrm{E}$ foi criada por uma demanda que a FINEP fez para alguns cientistas, no sentido de transformar resultados de pesquisas em produtos. A empresa $\mathrm{F}$ fez uso de programas de exportação governamental, que incentivaram e auxiliaram o empresário para que fosse realizado com sucesso o processo de internacionalização da empresa; houve também parceria da empresa com a Secretaria do Meio Ambiente, visto que o empreendedor é sócio do Fórum Gaúcho de Produção e Consumo Sustentável, e a empresa passou à Secretaria de Governo informações importantes de pesquisa que influenciaram nas novas regras da Lei da Aviação Agrícola.

\section{Conclusão}

Constatou-se uma forte relação das empresas com a universidade no que tange à captação de recursos humanos qualificados, bem como de utilização da infraestrutura universitária. As empresas investem no desenvolvimento de recursos humanos qualificados. Um exemplo disso são as empresas que financiam a pós-graduação do seu quadro de funcionários. Em linhas gerais, as empresas se beneficiam das possibilidades oferecidas pelo ambiente acadêmico, e este pode ser um fator decisivo no desenvolvimento e implementação de inovações que alcancem o mercado externo. Portanto, os mecanismos de interação das empresas com a universidade são relevantes para o desenvolvimento das mesmas, bem como o de seus produtos e/ou processos, e, consequentemente, para a internacionalização. Já na interação com o Estado, os entraves, principalmente referentes aos incentivos governamentais, são recorrentes, conforme os entrevistados. Há um descontentamento em relação ao difícil acesso ao financiamento governamental. Apesar de existirem diversos recursos públicos disponíveis, e os empreendedores reconhecem isso, as empresas encontram inúmeras barreiras para acessá-los. Este pode ser um dos entraves no processo de inovação e de internacionalização das empresas, pois o acesso a estes recursos 
diminuiria os elevados custos da atividade inovativa, e facilitaria o desenvolvimento de inovações mais competitivas.

\section{Referências}

CARneiro, A. P. M. (2005). Estudo da importância da inovação tecnológica no Brasil e da influência da gestão na estratégia de inovação - apresentação do cenário de inovação nas empresas industriais brasileiras através da pesquisa de inovação (PINTEC). 150 p. Dissertação (Mestrado em Sistema de Gestão) - Universidade Federal Fluminente, UFF, Niterói. Disponível em: <http://www.bdtd.ndc.uff.br/tde arquivos/14/ TDE-2008-10-30T162423Z-1741/Publico/Dissertacao\%20Ana\%20Morgado.pdf>.

CASTells, M. (1999). A sociedade em rede. São Paulo, Paz e Terra.

De Negri, J. A. (2005). “Padrões tecnológicos e de comércio exterior das firmas brasileiras”. In: De NeGRI, J. A.; SALERno, M. S. Inovações, padrões tecnológicos e desempenho das firmas industriais brasileiras. Brasília, IPEA.

Eтzкоwitz, H. (2009). Hélice tríplice: universidade-indústria-governo: inovação em ação. Porto Alegre, EDIPUCRS.

Guimarães, S. et al. (2012). Construção da inovação através de redes de cooperação universidade-empresa: análise das iniciativas e estratégias de cooperação no Rio Grande do Sul. Disponível em: <http://www.ufrgs.br/ppgsocio/Pojeto Final Inova\%E7\%E3o.pdf>.

GUIMARÃES, S. K. (2012). "International entrepreneurship in an emergent economy". In: BuRger-HeLmCHEN, T. (Org.). Entrepreneurship: gender, geographies and social context. Rijeka, Intech, p. 235-248.

IBGE, Instituto Brasileiro de Geografia e Estatística (2008). Pesquisas de inovação tecnológica - PINTEC. Disponível em: <http://www.pintec.ibge.gov.br/downloads/ PUBLICACAO/Publicacao\%20PINTEC\%202008.pdf>.

OCDE, Organização para a Cooperação e o Desenvolvimento Econômico (2004). Manual de Oslo - proposta e diretrizes para coleta e interpretação de dados sobre inovação tecnológica. Traduzido por FINEP. Brasília, 136 p. Disponível em: < http:// download.finep.gov.br/imprensa/manual de oslo.pdf>.

RuZziER, M; HiSRICH, R. D.; ANTONCIC, B. (2006). "SME internationalization research: past, present and future". Journal of small business and enterprise development, vol. 13, n. 4, p. 476-497.

Recebido em dezembro/2012 Aprovado em fevereiro/2013 